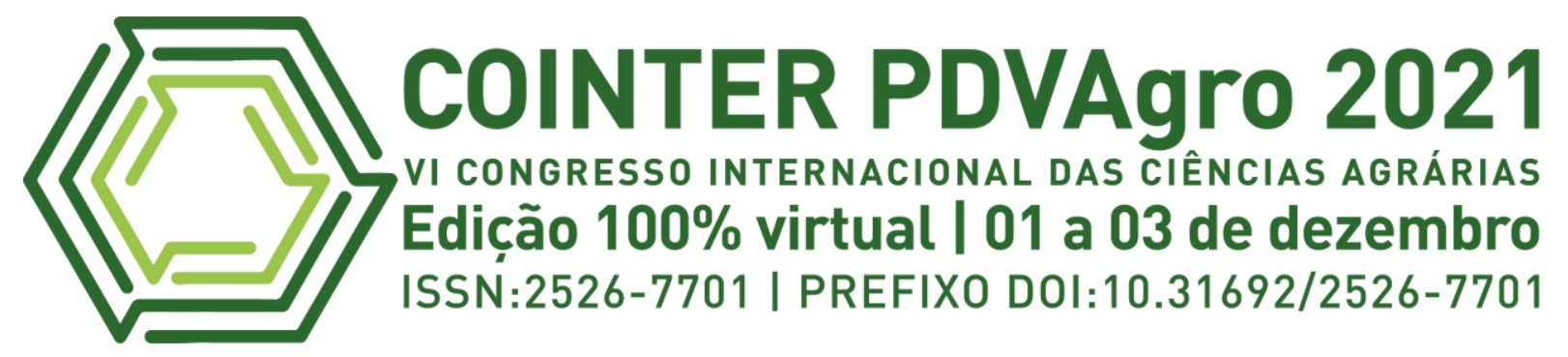

\title{
GERENCIAMENTO HÍDRICO NA SUINOCULTURA DO CENTRO ESTADUAL INTEGRADO DE EDUCAÇÃO RURAL - CEIER - VILA PAVÃO
}

\author{
GESTIÓN DEL AGUA EN LA PORCINA DEL CENTRO ESTATAL DE \\ EDUCACIÓN RURAL INTEGRADA - CEIER - VILA PAVÃO
}

\section{WATER MANAGEMENT IN THE SWINE FARMING OF THE INTEGRATED RURAL EDUCATION STATE CENTER - CEIER - VILA PAVÃO}

\author{
Apresentação: Comunicação Oral \\ Erica Durães Reetz ${ }^{1}$; Alessandra Ratzke Gueze ${ }^{2}$; Rodrigo Alves Macêdo ${ }^{3}$; Kaique Bastos Cardoso ${ }^{4}$; Ismael \\ Lourenço de Jesus Freitas 5
}

DOI: https://doi.org/10.31692/2526-7701.VICOINTERPDVAgro.0208

\begin{abstract}
RESUMO
Na suinocultura, a água se configura como um recurso vital e essencial para a produção, especialmente devido à sua necessidade para a dessedentação dos suínos durante o crescimento e desenvolvimento nas diversas fases fisiológicas da cadeia de produção. Diante do exposto este trabalho teve como objetivo monitorar a eficiência do processo produtivo da suinocultura da escola CEIER - Vila Pavão, em função do uso da água. O experimento foi realizado no Centro Estadual Integrado de Educação Rural- CEIER, localizado no município de Vila Pavão, Região Norte do Estado do Espírito Santo. O processo de estimativa da água seguiu os seguintes parâmetros: vazão dos bebedouros antigos, vazão dos bebedouros novos, economia de água, vazão da mangueira para a higienização, quantidade de água utilizada para a higienização e estimativa da quantidade de água ingerida por animal. A quantidade de água total utilizada na produção de suínos da escola CEIER de Vila Pavão, foi o somatório da quantidade de água utilizada para a higienização da suinocultura e a estimativa da quantidade de água por animal. De acordo com os resultado obtidos com o monitoramento da eficiência do processo produtivo de suínos da escola CEIER - Vila Pavão, em função do uso da água, conclui-se que, para a higenização da suinocultura da escola CEIER de Vila Pavão são consumidos 562,06 litros de água por dia. Antes da troca dos equipamentos de hidratação dos suínos eram gastos diáriamente um total de água em torno de 3.764,39 litros de água por dia. Equivalente a 289,57 litros por animal dia. Após a troca e manutenção dos equipamentos de dessedentação dos suínos, passaram a ser gastos em média de 660,06 litros de água por dia, com uma economia de 3.104,33 litros de água por dia. A média de água consumida por animal
\end{abstract}

\footnotetext{
1 Técnico em agropecuária, Centro Estadual Integrado de Educação Rural - CEIER - Vila Pavão - ES, ericaduraesreetz8@gmail.com

2 Técnico em agropecuária, Centro Estadual Integrado de Educação Rural - CEIER - Vila Pavão - ES, alessandragueze@gmail.com

3 Técnico em agropecuária, Centro Estadual Integrado de Educação Rural - CEIER - Vila Pavão - ES, rodrigo.macedo@aluno.edu.es.gov.br

4 Técnico em agropecuária, Centro Estadual Integrado de Educação Rural - CEIER - Vila Pavão - ES, kaiquebastoscardoso07@gmail.com

${ }^{5}$ Doutor em Produção Vegetal, Centro Estadual Integrado de Educação Rural - CEIER - Vila Pavão - ES, ismaelljif@yahoo.com.br
} 
dia passou para 50,77 litros/dia. O consumo de água da suinocultura da escola CEIER de Vila Pavão, estão muito acima dos padrões nacionais de produção, havendo a necessidade de correções e adaptações.

Palavras-Chave: Água, suínos, produção animal.

\title{
RESUMEN
}

En la producción porcina, el agua es un recurso vital y esencial para la producción, especialmente por su necesidad de dar agua a los porcinos durante el crecimiento y desarrollo en las diferentes fases fisiológicas de la cadena productiva. Dado lo anterior, este trabajo tuvo como objetivo monitorear la eficiencia del proceso de producción de la cría de cerdos en la escuela CEIER - Vila Pavão, en función del uso del agua. El experimento se llevó a cabo en el Centro Estatal Integrado de Educación Rural CEIER, ubicado en el municipio de Vila Pavão, Región Norte del Estado de Espírito Santo. El proceso de estimación del agua siguió los siguientes parámetros: bebederos antiguos, bebederos nuevos, ahorro de agua, caudal de manguera para limpieza, cantidad de agua utilizada para limpieza y estimación de la cantidad de agua ingerida por animal. La cantidad de agua total utilizada en la producción de cerdos en la escuela CEIER en Vila Pavão, fue la suma de la cantidad de agua utilizada para la higiene de los cerdos y la estimación de la cantidad de agua por animal. De acuerdo con los resultados obtenidos con el seguimiento de la eficiencia del proceso de producción porcina en la Escuela CEIER - Vila Pavão, dependiendo del uso de agua, se concluye que, para la limpieza de la cría de cerdos en la Escuela CEIER en Vila Pavão Se consumen 562,06 litros de agua al día. Antes de cambiar el equipo de hidratación de los cerdos, se utilizaba diariamente un total de alrededor de 3.764,39 litros de agua por día. Equivalente a 289,57 litros por animal y día. Luego de cambiar y mantener el equipo de bebederos de cerdos, se utilizó una media de 660,06 litros de agua por día, con un ahorro de 3.104,33 litros de agua por día. El promedio de agua consumida por animal por día aumentó a 50,77 litros / día. El consumo de agua de la escuela de cerdos CEIER en Vila Pavão está muy por encima de los estándares nacionales de producción, con la necesidad de correcciones y adaptaciones.

Palabras Clave: Agua, porcinos, producción animal.

\begin{abstract}
In swine production, water is a vital and essential resource for production, especially due to its need for watering the swine during growth and development in the different physiological phases of the production chain. Given the above, this work aimed to monitor the efficiency of the production process of pig farming at the CEIER school - Vila Pavão, depending on the use of water. The experiment was carried out at the Integrated State Center for Rural Education - CEIER, located in the municipality of Vila Pavão, Northern Region of the State of Espírito Santo. The water estimation process followed the following parameters: old drinking fountains, new drinking fountains, water saving, hose flow for cleaning, amount of water used for cleaning and estimating the amount of water ingested per animal. The amount of total water used in the production of pigs at the CEIER school in Vila Pavão, was the sum of the amount of water used for swine hygiene and the estimate of the amount of water per animal. According to the results obtained with the monitoring of the efficiency of the pig production process at the CEIER School - Vila Pavão, depending on the use of water, it is concluded that, for the cleaning of the pig farming at the CEIER School in Vila Pavão, 562.06 liters are consumed of water per day. Before changing the hydration equipment for the pigs, a total of water around 3,764.39 liters of water per day was used daily. Equivalent to 289.57 liters per animal per day. After changing and maintaining the swine watering equipment, an average of 660.06 liters of water per day was used, with savings of 3,104.33 liters of water per day. The average of water consumed per animal per day increased to 50.77 liters/day. The consumption of water from the CEIER school in Vila Pavão swine is far above the national production standards, with the need for corrections and adaptations.
\end{abstract}

Keywords: Water, swine, animal production. 


\section{INTRODUÇÃO}

A suinocultura é uma atividade em expansão no mercado mundial. O Brasil está entre os principais produtores, ocupando o quarto lugar no ranking, com 4,436 milhões de toneladas produzidas anualmente, sendo 1,024 milhões de toneladas exportadas para 70 países (ABPA, 2021).

No planejamento nas instalações rurais de um sistema de produção de suínos, normalmente, o fator mais desprezado pelos projetistas e, nem por isso menos importante, é aquele relacionado com a água. A suinocultura é, sem dúvida, uma atividade importante do ponto de vista social, econômica e, especialmente, como instrumento de fixação do homem ao campo. No entanto, sua exploração é considerada pelos órgãos de controle ambiental, como "atividade potencialmente causadora de degradação ambiental", sendo enquadrada como de grande potencial poluidor (OLIVEIRA, 2002).

O excesso ou a falta de água na produção de suínos é prejuízo. Sem acesso à água de qualidade, os animais não se alimentam direito e a produtividade cai. Por isso, esse recurso está entre as principais preocupações do suinocultor. Graças a avanços na produção, novas tecnologias e adoção de boas práticas, um suíno hoje consegue consumir a metade de água que era utilizada há cerca de 30 anos. O desafio é fazer com que os produtores brasileiros saibam como isso é possível (EMBRAPA, 2021).

Com as mudanças significativas que ocorreram na genética, nutrição e instalações nas últimas décadas, houve uma redução no consumo de água e a produção de dejetos. De acordo com EMBRAPA, (2021), os produtores que melhor usam a água, consomem em torno de 4,5 litros por suíno por dia. Os de pior resultado superam os 11 litros. Essa diferença está ligada principalmente ao manejo e equipamentos disponíveis aos produtores. Soluções simples podem render bons resultados e ganho econômico.

Água desperdiçada influencia diretamente no custo para tratar e distribuir o dejeto. Diante do exposto este trabalho teve como objetivo monitorar a eficiência do processo produtivo da suinocultura da escola CEIER - Vila Pavão, em função do uso da água. 


\section{FUNDAMENTAÇÃO TEÓRICA}

O Brasil vem se destacando na pecuária mundial, dentre os principais fatores que contribuem para esse sucesso, é a disponibilidade de recursos hídricos, sendo esse um tema pouco abordado nas pesquisas, porém, de fundamental importancia para a produção animal (SNA, 2021).

Nos tempos modernos da agricultura, a quantidade e os reservatório de água são assuntos de fundamental importância. A elevação dos índices de degradação e da poluição nos recursos naturais tem levado os pesquisadores, a realizar estudos sobre as causas e efeitos da produção primária no meio ambiente (OLIVEIRA, 2002a). A alta demanda por água, especialmente em regiões de produção pecuária intensiva, reduz a qualidade e disponibilidade principalmente nas reservas naturais de água (fontes superficiais e subterrâneas) que suprem as necessidades primárias dos animais (OLIVEIRA, 2002a; ALADENOLA; ADEBOYE, 2010). A intensificação da produção suína tem direcionado ao aumento do consumo de água. Isto associado às sujeições ambientais subentendidos pela redução drástica das reservas, levou ao surgimento de maiores pressões na sua utilização como insumo à produção (FERREIRA et al., 2007; LANA, 2009).

A água pode ser considerada como um dos elementos mais importantes para a produção de suínos. Sem ela, em quantidade e qualidade adequada, não há como produzir bem. Já está provado que não se pode pensar em produção sustentável sem uma boa gestão da água na produção animal (EMBRAPA, 2021).

É de grande importância o conhecimento do volume gasto de água na produção de suínos. Isso permite avaliar se o consumo de água da propriedade está dentro de padrões normais estabelecidos (SOUZA, 2017).

Na produção de suínos, a água é um recurso vital e essencial para a produção, em particular devido à sua necessidade para a hidratação dos suínos durante o crescimento e desenvolvimento nas diversas fases fisiológicas da cadeia de produção (FERREIRA et al., 2007). Contudo, o modelo de consumo pode variar de produtor para produtor de acordo com os diferentes tipos de equipamentos instalados para a dessedentação dos suínos, o consumo de água aparece como uma missão complicada de ser definida. Além do volume ingerido pelos animais, outros usos pela sua importância devem ser considerados e mensurados, a exemplo, outros equipamentos utilizados, água dos balneários e sanitários (OLIVEIRA, 2002a; FERREIRA et al., 2007). 
As utilizações mais relevantes da água na suinocultura são para a dessedentação animal, o hidratação da ração, a nebulização e o programa de higiene e desinfecção das granjas (OLIVEIRA, 2002a; FERREIRA et al., 2007; LIMA, 2007; TAVARES; OLIVEIRA, BELLI FILHO, 2012). Contudo, tais processos sofrem ação de varios fatores, como a fisiologia animal, as circunstâncias técnicas e tecnológicas de dessedentação e alimentação, as construções dos edifícios, as práticas de higiene e limpeza e as condições ambientais das salas de produção (EUROPEAN UNION, 2003; SHAW et al., 2000; FERREIRA et al., 2004; OLIVEIRA e SILVA, 2006; FERREIRA et al., 2007; LIMA, 2007).

Em se tratando do desperdício de água na suinocultura, os elementos fortemente responsáveis são produzidos, principalmente, pela ruptura do sistema hidráulico, pelo desperdício dos suínos nos equipamentos para a hidratação animal e por deslecho dos produtores (por exemplo, na demora da reparação de equipamentos e no procedimento de lavagem) (MARIANI, 2008).

Para a redução do problema do alto consumo de água na suinocultura é possível citar a diminuição de desperdícios na hidratação animal e todas as restantes tarefas não relacionadas diretamente com a alimentação dos animais (EUROPEAN COMISSION, 2003). Há necessidade de economizar no uso da água nas instalações por meio de procedimentos como o desencaminhamento das águas pluviais (calhas), elevação dos beirais, instalação de equipamentos eficientes para a dessedentação animal, manutenção da rede e do sistema hidráulico para a manter a pressão, e a vazão uniforme em todos os equipamentos (OLIVEIRA, 2006).

A suinocultura é uma atividade que demanda por recursos hídricos para o seu bom funcionamento (dessedentação, lavagem das instalações e bem-estar animal), é impressindível o conhecimento dos volumes de água consumidos e a sua qualidade, pois além de ser um indicador do desempenho zootécnico e da saúde dos animais, também permite determinar o custo da água na unidade de produção (PALHARES, 2021).

\section{METODOLOGIA}

O experimento foi realizado no Centro Estadual Integrado de Educação Rural- CEIER, localizado no município de Vila Pavão, Região Norte do Estado do Espírito Santo.

O processo de estimativa da água seguiu os seguintes parâmetros: vazão dos bebedouros antigos, vazão dos bebedouros novos, economia de água, vazão da mangueira para a higienização, quantidade de água utilizada para a higienização e estimativa da quantidade de água ingerida por animal. 
Para a vazão da mangueira para higienização, vazão dos bebedouros antigos e novos (tipo chupeta) e a vazão dos vazamentos identificados, foram coletados o volume de água em um becker graduado de $1.000 \mathrm{mls}$, em um intervalo de 10 segundos, em quatro repetições.

A quantidade de água utilizada para a higienização da suinocultura foi mensurada em cinco dias consecutivos, de acordo com o tempo de uso de água para higienizar cada baia, e de acordo com a vazão da mangueira calculada.

A estimativa da quantidade de água por animal; será realizada de acordo com as tabelas 1 e 2 .

Tabela 01: Água necessária para a produção de suínos, em função do estado fisiológico, nas diferentes fases produtivas.

\begin{tabular}{cc}
\hline Categoria de Suíno & Aporte de água (L/d) \\
\hline Leitões $(15 \mathrm{~kg})$ & $1,5-2$ \\
Suíno $(50 \mathrm{~kg})$ & $5-8$ \\
Suíno $(90 \mathrm{~kg})$ & $6-9$ \\
Suíno $(150 \mathrm{~kg})$ & $7-10$ \\
Porca em gestação & $15-20$ \\
Porca em lactação & $30-40$ \\
\hline
\end{tabular}

Fonte: Bonazzi et al. (2001)

Tabela 02: Exigências de água (L/animal/dia) de acordo com a fase do ciclo de produção e vazão mínima do bebedouro.

\begin{tabular}{ccc}
\hline & \multicolumn{2}{c}{ Exigências } \\
\cline { 2 - 3 } Fase & Mínima & Máxima \\
\hline Leitão lactante & 0,1 & 0,5 \\
Creche & 1,0 & 5,0 \\
Suínos $(25-50 \mathrm{~kg})$ & 4,0 & 7,0 \\
Suínos $(50-100 \mathrm{~kg})$ & 5,0 & 10,0 \\
Porcas em lactação & 20,0 & 35,0 \\
Porcas gestação & 15,0 & 23,0 \\
Cachaços & 10,0 & 15,0 \\
\hline Fonte: Adaptado da EMBRAPA/CMPSA (1994) e Bodman (1994).
\end{tabular}

Para quantidade de água usada por baia antes e depois da troca dos bebedouros, foi mensurada de acordo com a quantidade de água utilizada para a higienização da suinocultura, bem como a vazão dos bebedouros antigos e novos de cada baia e estimativa da quantidade de água por animal.

A quantidade de água total utilizada na produção de suínos da escola CEIER de Vila Pavão, foi o somatório da quantidade de água utilizada para a higienização da suinocultura e a estimativa da quantidade de água por animal.

Os dados foram submetidos a análise qualitativas e resultados foram plotados com o auxílio do programa computacional Microsoft Excel $^{\circledR}$. 


\section{RESULTADOS E DISCUSSÃO}

Na figura 01 é possível observar a desuniformidade entre as vazões, bem como alguns vazamentos dos bebedouros dos animais nas nove baias da suinocultura da escola CEIER de Vila Pavão. Nota-se que as baias 2, 3, 5 e 7, foram as que apresentaram maiores vazões, com valores de 4,95, 3,98, 3,82 e 4,16 litros/minuto, respectivamente. De acordo com Bodman (1994), as vazões ideais para os suínos, dependendo da fase fisiológico dos animais, variam em torno de 0,2 a 2,0 litros/minuto. O que demonstra falhas nos equipamentos de dessedentação animal. Com tudo, foram encontrados vazamentos nas baias 5, 6 e 7, com vazões de 0,19, 0,20 e 2,34 litros/minuto. Esses vazamentos podem gerar um desperdício de 3.104,33 litros de água por dia, valores batante expressivos. O que comprova a necessidade de substituições dos bebedouros.

Figura 01: Vazão dos bebedouros antigos e vazamentos por baia encontrados na suinocultura da escola CEIER de Vila Pavão.

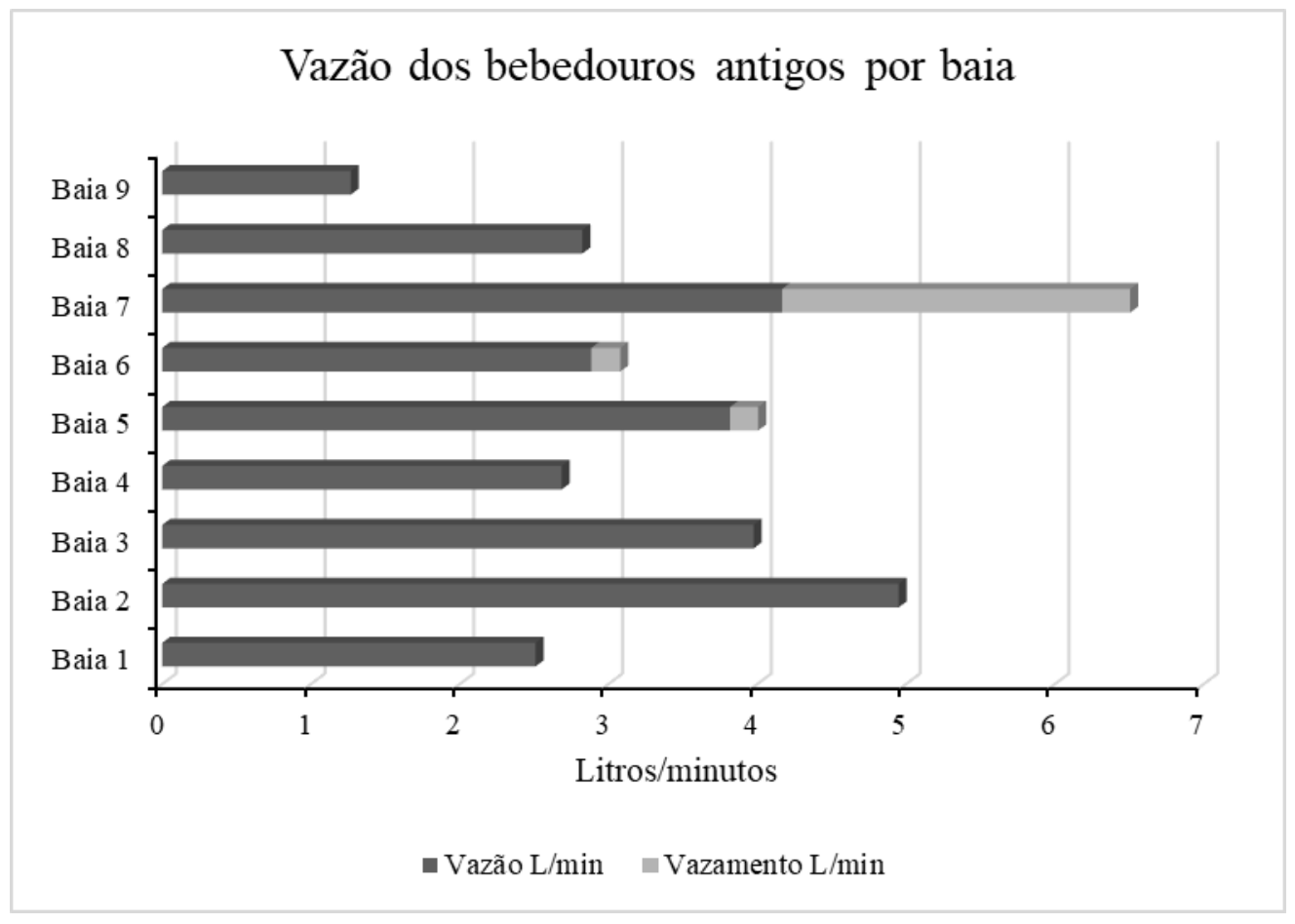

Fonte: Própria (2021).

Após a substiuição dos bebedouros, observou-se na figura 02 , uma redução das vazões variando de 1,5 a 2 litros/minuto, o que se encontra dentro das faixas ideias que são de 0,2 a 2,0 litros por minuto, de acordo com Bodman, (1994). Além disso, não foram detectados vazamentos em nunhma das nove baias avaliadas. 
Figura 02: Vazão dos bebedouros novos e vazamentos por baia, encontrados na suinocultura da escola CEIER de Vila Pavão.

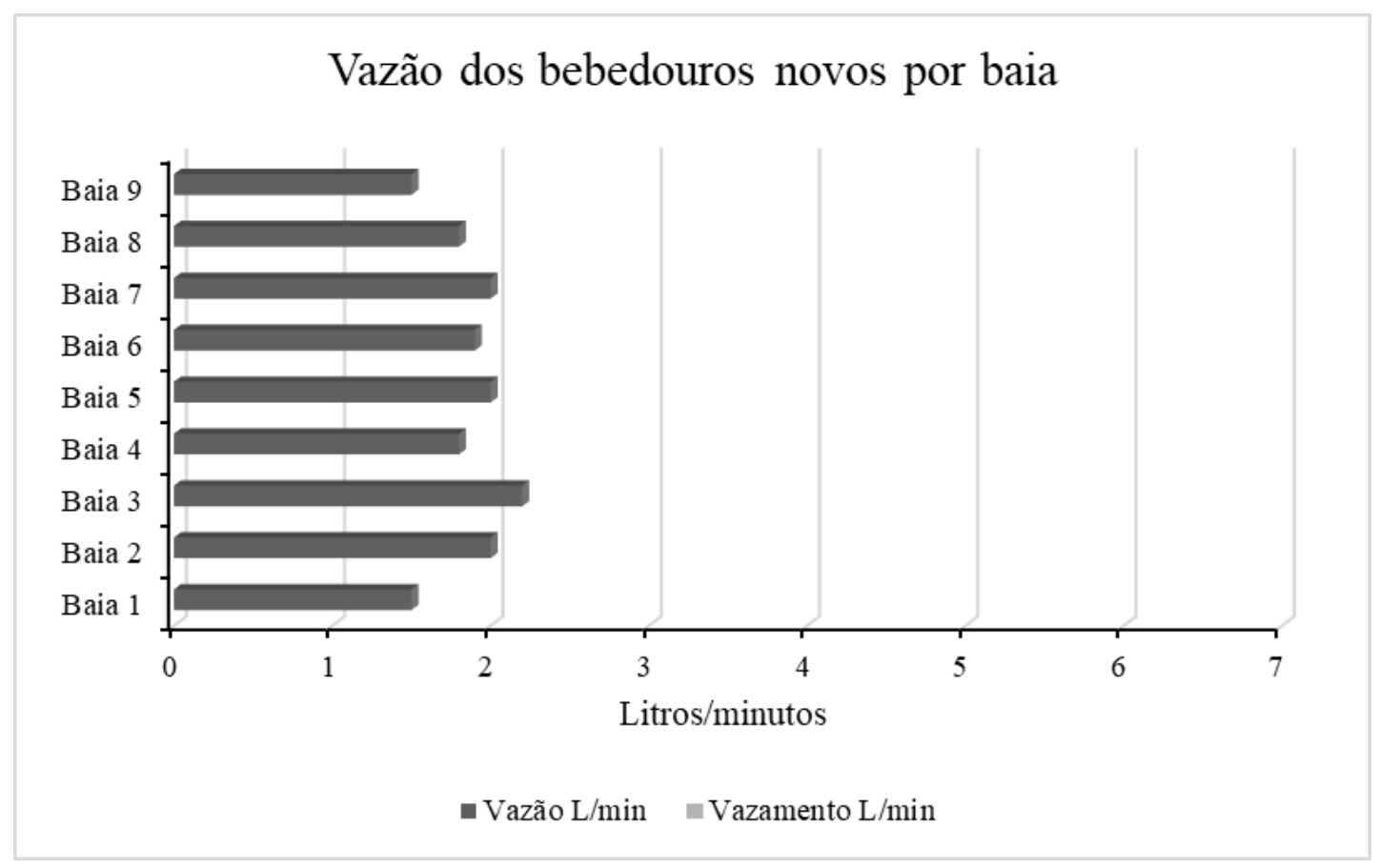

Fonte: Própria (2021).

Na figura 03, observa-se uma redução siginificativa do despeerdício de água na suinocultura da escola CEIER de Vila Pavão, após a troca e manutenção dos equipamentos de dessedentação dos suínos, com redução das vazões dos bebedouros para a faixas ideias, bem como a eliminação de vazamentos. De acordo com a EUROPEAN COMISSION (2021), são considerados medidas mais relevantes para a redução do consumo de água pelos suínos, a redução de desperdícios na dessedentação animal e todas as restantes tarefas não relacionadas diretamente com a alimentação dos animais, como por exemplo, a higinizaçao das baias e a eliminação de vazamentos das tubulações e bebedouros. 
Figura 03: Coparação das vazões dos bebedouros antigos e novos e vazamentos por baia, encontrados na suinocultura da escola CEIER de Vila Pavão.

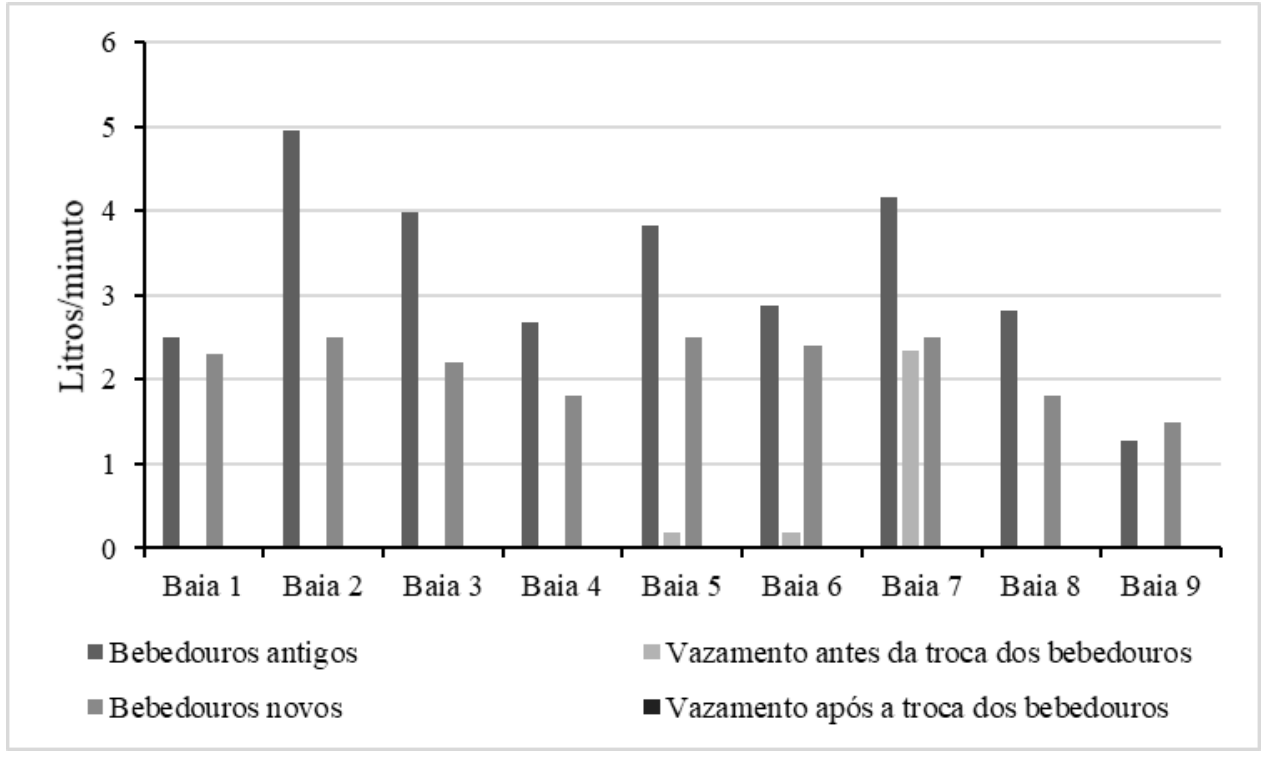

Fonte: Própria (2021)

Na suinocultura moderna, deve-se reduzir o uso das águas nas instalações através do desvio das águas pluviais (calhas), aumento dos beirais, instalação de equipamentos eficientes para a hidratação animal, manutenção da rede e do sistema hidráulico para a manter a pressão, e a vazão uniforme em todos os equipamentos (EMBRAPA, 2021). O que não vinha sendo feito durante muitos anos da suinocultura da escola CEIER de Vila Pavão.

Na tabela 03, são apresentados o número de animais com seus respctivos pesos e fases fisiológicas, com a estimativa de consumo de água segundo EMBRAPA/CMPSA (1994) e Bodman (1994). Nota-se que existem 13 animais em diferentes fases de desenvolvimento, sendo a porca em lactação o animal com maior consumo de água por dia, com valor estimado de 40 litros/dia. O total de consumo diário de água pelos 13 suínos, foram estimádos em 98 litros de água por dia. 
Tabela 03: Exigências de água (L/animal/dia) de acordo com a fase do ciclo de produção e peso dos animais da suinocultura da escola CEIER de Vila Pavão.

\begin{tabular}{ccc}
\hline Suíno & Peso $(\mathbf{K g})$ & Quantidade de água por dia \\
\hline Cachaço & $96 \mathrm{Kg}$ & $15 \mathrm{~L}$ \\
Porca em lactação & $122 \mathrm{Kg}$ & $40 \mathrm{~L}$ \\
Porca & $90 \mathrm{Kg}$ & $9 \mathrm{~L}$ \\
Porca & $107 \mathrm{Kg}$ & $9 \mathrm{~L}$ \\
Porca & $86 \mathrm{Kg}$ & $9 \mathrm{~L}$ \\
5 Leitões (creche) & $9,5 \mathrm{Kg}$ & $10 \mathrm{~L}$ \\
3 Leitões & $4,1 \mathrm{Kg}$ & $6 \mathrm{~L}$ \\
\hline
\end{tabular}

Fonte: Própria (2021), adaptado da EMBRAPA/CMPSA (1994) e Bodman (1994).

Estimar o consumo de água na propriedade é estremamente complicado, pois existe variação de inúmeros fatores como, por exemplo, o volume que o animal precisa ingerir para a sua sobrevivência (OLIVEIRA, 2002a; FERREIRA et al., 2007). Além disso, a idade, a fase fisiológica ou ciclo reprodutivo, o peso vivo do animal, a qualidade da água (temperatura, salinidade e microbiologia), o tipo de equipamento para a dessedentação, o modelo de instalação, o fluxo de água, a quantidade e qualidade da dieta (teor de matéria seca e proteína da dieta, fibra e palatibilidade), o tipo de piso (maior consumo para pisos sem cama), as condições ambientais (temperatura e umidade relativa), o estado de saúde dos animais, diferenças nas condições ambientais, nas características fenotípicas e individuais de cada animal, também podem dificultar essa estimativa (PERDOMO, 1995; BONETT; MONTICELLI, 1998; THACKER, 2001; OLIVEIRA, 2002a; BRUMM, 2006; PALHARES, 2021).

O conhecimento das necessidades diárias dos suínos e do seu padrão de consumo durante o dia na unidade, permite o dimensionamento correto dos sistemas de armazenamento e fornecimento de água para os animais. Desvios no consumo poderão ser indicadores de problemas na saúde animal (TAVARES, 2012).

Consumo de água para a higienização da suinocultura é um fotor de fundamental importancia. Nota-se que o consumo de água para a higienização da suinocultura varia de acordo com o tempo gasto na limpeza e a vazão da mangueira. Ou seja, quanto maior tempo gasto para se fazer higienização maior é o consumo de água. No segundo dia de avaliação, gastou-se maior tempo para se realizar a limpeza nos dois turnos de 11,73 minutos, com uma 
vazão de 54,075 litros/minuto de água da mangueira, o consumo foi de 634,30 litros. A média dos 5 dias de avaliação foi de 562,06 litros de água gastos para a higinização da suinocultura da escola CEIER de Vila Pavão, por dia.

Figura 04: Consumo de água para a higienização da suinocultura da escola CEIER de Vila Pavão.

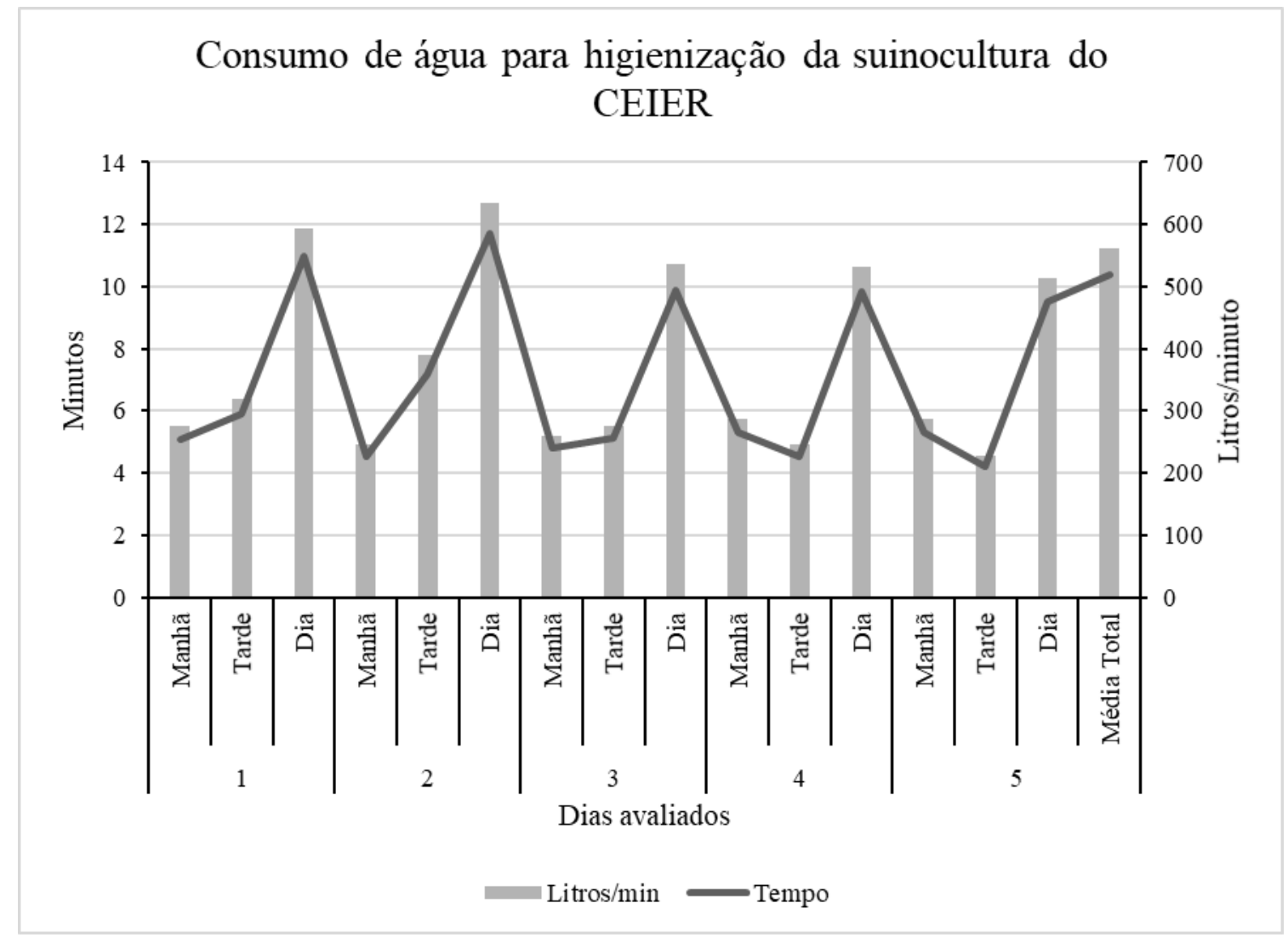

Fonte: Própria (2021).

O aumento do consumo de água no procedimento de limpeza por desperdício é comum, pois grande parte dos produtores, ao invés de usarem máquinas de jatos de água sob pressão, utilizam mangueiras de vazão alta (SINOTTI, 2005). O fato da criação intensiva na fase de cescimento/terminação incluir pisos de concreto completos na maioria das unidades, a remoção de dejetos é feita com o uso de grandes volumes de água (PAULO, 2003). O que foi observado na suinocultura da escola CEIER de Vila Pavão.

No montante total de consumo de água da suinocultura da escola CEIER de Vila Pavão, eram gastos diáriamente um total de água em torno de 3.764,39 litros de água por dia. Equivalente a 289,57 litros por animal dia. Após a troca e manutenção dos equipamentos de dessedentação dos suínos, passaram a ser gastos em média de 660,06 litros de água por dia, com uma economia de 3.104,33 litros de água por dia. A média de água consumida por animal dia passou para 50,77 litros/dia. De acordo com EMBRAPA, (2021), os produtores que melhor 
usam a água, consomem em torno de 4,5 litros por suíno por dia. Os de pior resultado superam os 11 litros. Ou seja, o consumo de água da suinocultura da escola CEIER de Vila Pavão, estão muito acima dos padrões nacionais de produção.

\section{CONCLUSÕES}

De acordo com os resultado obtidos com o monitoramento da eficiência do processo produtivo de suínos da escola CEIER - Vila Pavão, em função do uso da água, conclui-se que:

$\checkmark \quad$ Para a higenização da suinocultura da escola CEIER de Vila Pavão são consumidos 562,06 litros de água por dia.

$\checkmark \quad$ Antes da troca dos equipamentos de hidratação dos suínos eram gastos diáriamente um total de água em torno de 3.764,39 litros de água por dia. Equivalente a 289,57 litros por animal dia.

Após a troca e manutenção dos equipamentos de dessedentação dos suínos, passaram a ser gastos em média de 660,06 litros de água por dia, com uma economia de 3.104,33 litros de água por dia. A média de água consumida por animal dia passou para 50,77 litros/dia.

O consumo de água da suinocultura da escola CEIER de Vila Pavão, estão muito acima dos padrões nacionais de produção, havendo a necessidade de correções e adaptações nas instalações.

\section{REFERÊNCIAS}

ABPA - Associação Brasileira De Proteína Animal. Suinocultura. Disponível em: <http://abpabr.org/wp-content/uploads/2021/04/ABPA_Relatorio_Anual_2021_web.pdf>. Acesso em: 16 de junho de 2021.

ALADENOLA, Olanike Olowoiya; ADEBOYE, Omotayo. Assessing the potential for rainwater harvesting. Water Resources Management, v. 24, n. 10, p. 2129-2137, 2010.

BODMAN, G.R. 1994. Evaluation of housing and environmental adequacy: Principles and concepts. Cooperative Extension at the University of Nebrasca, Lincoln, 28p.

BONAZZI, G. Liquami Zootecnici. Manuale per l'utilizzazione agronomica. CRPA-Centro Ricerche Produzioni Animali, Reggio Emilia, Italia. Edizioni L'Informatore Agrario, 2001, 320 p.

BONETT, L. P.; MONTICELLI, C. J. (Ed.). Suínos: o produtor pergunta, a Embrapa responde. (Coleção 500 Perguntas 500 Respostas) 2. ed. Brasília: Embrapa-SPI; Concórdia: Embrapa Suínos e Aves, 243p. 1998. 
BRUMM, M. Patterns of Drinking Water Use in Pork Production Facilities. In: Nebraska swine report. Institute of Agriculture and Natural Resources, Nebraska. 2006, p. 10-13.

EMBRAPA - Empresa Brasileira de Pesquisa Agropecuária. Gerenciamento hídrico na suinocultura reduz uso da água em até $\mathbf{5 0 \%}$. Disponível em: < https://www.embrapa.br/busca-de-noticias/-/noticia/2506249/gerenciamento-hidrico-nasuinocultura-reduz-uso-da-agua-em-ate-50 >. Acesso em: 16 de junho de 2021.

EMBRAPA/CNPSA. 1994. Dia de Campo sobre manejo e utilização de dejetos suínos, 1994. 47p.

EUROPEAN UNION. Council directive 91/676/EEC: concerning the protection of waters against pollution caused by nitrates from agricultural sources. Disponível em: < https://ec.europa.eu/environment/water/water-nitrates/index_en.html> Acesso em: 22 de setembro de 2021.

FERREIRA, L., DUARTE, E., ELÓI, M., FARIA, P. Uso da água em explorações suinícolas intensivas, no contexto da diretiva PCIP - Implicações associadas à produção de chorumes. In: CONFERÊNCIA NACIONAL SOBRE A QUALIDADE DO AMBIENTE, 8., 2004, Lisboa, Portugal. Lisboa: Universidade Nova de Lisboa (Eds), v. 1, 2004. p 349-350.

FERREIRA, L., DUARTE, E., TAVARES, J., FITAS da CRUZ, V. A importância da gestão integrada da água:novos desafios para a gestão ambiental no sector suinícola. In: CONGRESO IBERICO, 1., Y CONGRESO NACIONAL DE AGROINGENIERÍA, 4., 2007, Albacete, Espanha, 2007. p. 104-106.

LANA, R. Uso racional de recursos naturais não-renováveis: aspectos biológicos, econômicos e ambientais. Revista Brasileira de Zootecnia [suplemento especial], v. 38, p. 330-340, 2009.

LIMA, G. Nutrição de suínos - Ferramenta para reduzir a poluição causada pelos dejetos e aumentar a lucratividade do negócio. In: SEGANFREDO, Milton (ed). Gestão ambiental na suinocultura. Brasília: Embrapa Informação Tecnológica, 2007. p. 63 -101.

MARIANI, L. Cadastro técnico multifinalitário aplicado à geração distribuída de energia a partir de biomassa residual de suinocultura. 2008. 101p. Dissertação (Mestrado) Programa de Pós-Graduação em Engenharia Civil, Centro Tecnológico, Universidade Federal de Santa Catarina. Florianópolis, 2008.

OLIVEIRA, P. A. V. Uso racional da água na suinocultura. Concórdia: Embrapa Suínos e Aves, 2002a. Curso de capacitação em práticas ambientais sustentáveis: treinamento 2002. p. 63-71.

OLIVEIRA, P. A.; SILVA, A. As edificações e os detalhes construtivos voltados para o manejo de dejetos na Suinocultura. Concórdia: Embrapa Suínos e Aves. PNMA II Programa Nacional do Meio Ambiente, 2006. 40p.

OLIVEIRA, Paulo Armando Victória de. Uso racional da água na suinocultura. Concórdia: Embrapa Suínos e Aves, 2002a. Curso de capacitação em práticas ambientais sustentáveis: treinamento, p. 63-71, 2002. 
PALHARES, J. C. O manejo hídrico na produção de suínos. Disponível em: <http://www.infoteca.cnptia.embrapa.br/bitstream/doc/905188/1/Aguasuinos.pdf >. Acesso em 23 de setembro de 2021.

PAULO, R. M. Uso de camas sobrepostas durante as fases de crescimento e terminação de suínos em condições de verão. 2003. 65p. Dissertação (Mestrado) - Programa de PósGraduação em Engenharia Agrícola, Universidade Federal de Viçosa. Viçosa, 2003.

PERDOMO, C. C. Uso racional da água no manejo de dejetos suínos. In: SEMINÁRIO MINEIRO SOBRE MANEJO E UTILIZAÇÃO DE DEJETOS DE SUÍNOS, 1., 1995, Ponte Nova, MG. Anais. Ponte Nova, MG. 1995, p. 8-23.

SHAW, M.; BEAULIEU, A. D.; PATIENCE, J. Effect of diet composition on water consumption in growing pigs. Journal of Animal Science, v. 84, n. 11 p. 3123-3132, 2006.

SINOTTI, A. P. S. Avaliação do volume de dejetos e da carga de poluentes produzidos por suíno nas diferentes fases do ciclo criatório. 2005. 85p. Dissertação (Mestrado) - Programa de Pós-Graduação em Agroecossistemas, Centro de Ciências Agrárias, Universidade Federal de Santa Catarina. Florianópolis, 2005.

SNA - Sociedade Nacional de Agricultura. Gerenciamento hídrico na suinocultura pode reduzir uso da água em até 50\%. Disponível em: < https://www.sna.agr.br/gerenciamentohidrico-na-suinocultura-reduz-uso-da-agua-em-ate-50/> Acesso em 17 de setembro de 2021.

SNA - Sociedade Nacional de Agricultura. Gerenciamento hídrico na suinocultura pode reduzir uso da água em até 50\%. Disponível em: < https://www.sna.agr.br/gerenciamentohidrico-na-suinocultura-reduz-uso-da-agua-em-ate-50/> Acesso em 17 de setembro de 2021.

SOUZA, J. C. P., OLIVEIRA, P. A. V., TAVARES, J. M., ZANUZZI, C. M., TREMEA, S. L., PIEKAS, F., ZIMMERMANN, L. A. Gestão da água na suinocultura. Concórdia: Embrapa Suínos e Aves, 2017.

SOUZA, J. C. P., OLIVEIRA, P. A. V., TAVARES, J. M., ZANUZZI, C. M., TREMEA, S. L., PIEKAS, F., ZIMMERMANN, L. A. Gestão da água na suinocultura. Concórdia: Embrapa Suínos e Aves, 2017.

TAVARES, J. M. R.; OLIVEIRA, P. A.; BELLI FILHO, P. Sustentabilidade da suinocultura - Reduções de consumo de água e de dejetos na produção animal. In: SIMPÓSIO LUSOBRASILEIRO DE ENGENHARIA SANITÁRIA E AMBIENTAL, 15., 2012, Belo Horizonte, MG. Rio de Janeiro, 2012. 10p.

THACKER, P. Water in Swine Nutrition. In: Swine Nutrition, 2nd Edition. Eds: Lewis, A.J. Southern. L.L. CRC Press. 2001. p. 381-398. 